\title{
Analyses of the Articles Published in Nigerian Journal of Animal Production
}

\section{S.O. Adewole and M.K. Ajala}

National Animal Production Research Institute, Ahmadu Bello University, P.M.B. 1096 Shika-Zaria, Nigeria.

\begin{abstract}
The analyses of the articles published in the Nigerian.Journal of Animal Production were examined by discipline, authorship pattern, institutional relationships, title and other biblometeric considerations. The data for this analyses were generated from the first and last decades of the publication of the Journal in 1974-1984 and 1991-2000. Seven hundred and eighty-seven (787) titles were published during the 20 years analyses with 472 titles published during the first decade and 315 titles between 1991-2000. Nutrition was the most researched discipline in animal production in Nigeria, contributing over $37 \%$ of the publications in the Journal. Five hundred and twenty-six (526) tiles were authored by more than one author, representing over $66 \%$ of the total authored titles. This confirms the trend of authorship in science and technology, while some evidence abound on institutional collaborations among scientists, particularly with peers outside the country.
\end{abstract}

Key words: Bibliometrics, analysis, publications.

\section{Introduction}

The analyses of the contents of scientific literature elucidate the composition of the subject make up of the discipline being analysed. One of the generally accepted methods of scientific investigation is indeed to follow the literature by the simplest means, and scientists have used various means and sources to gather information. These include regular reading of all available texts, recommendations from colleagues and superiors, references and citations in the texts and other related publications or a study of the literature of the affected subject entirely.

Information is recorded and multiplied by publishing units, which is a functional unit involved in the transfer of information from the source to users. The need for bibliographic control through proper examination, documentation, and organization is a functional requirement of information centers and libraries. Adewole (1991) examined some characteristics of the articles published in the Nigerian Journal of Animal Production (NJAP) leaving out some other areas with a view to allowing for future examination of their salient analyses. This hope has not been fulfilled even up till this work. It was, in fact, discovered that nobody had worked in the literature of animal agriculture, and so the need to complete the exercise, including information into 2000 . 
This study looks at the articles published by the Nigerian Journal of Animal Production in 20 years of ten consecutive volumes of the first and last decades of publication of the Journal, through distribution by discipline, number of titles, pattern of authorship, institutional relationship, etc.

Adewole (1989) used citation analysis to study the literature of animal production research through the Journal of Animal Production Research (JAPR) and observed that the literature of the subject area required more studies than had been done. In a cross analysis of the pattern of journal usage by scientists of the National Animal Production Research Institute (NAPRI), Adewole (1989) observed that through the examination of the core Journals used by the scientists, it could lead to the identification and subsequent acquisition of only relevant literature thereby eliminating wastage and saving time used on searching unnecessary and voluminous literature.

The traditional techniques of analysis have a long history, which has not yet been adequately documented. For instance, there is a fragmentary evidence of the catalogues of the Nlexandrian library of $250 \mathrm{BC}$ and a host of other medieval library catalogues. The idea of an entry word for each book as an access point in information search according to Vickery (1968) appeared as far back as 1545 and the earliest form of classification scheme and the development of thesaurus began through subject analyses.

\section{Materials and Methods}

The titles published by the Nigerian Journal of Animal Production (NJAP) from 1974-84; 19912000 , representing volumes $1-11,18-27$ were the main sources of data for this study. The first 10 volumes represented the first decade of the journal, while volumes 18-27, i.e. 1991-2000 represented the last decade of publication of the
Journal. The data gathered were arranged and grouped under the following:

(a) Number of titles published by volume

(b) Yearly pattern of distribution

(c) Distribution by discipline

(d) Authorship distribution

(e) Address(es) of author(s)

Twenty years bibliographic records is not only detailed enough to draw conclusion, but representative enough to douse any clout of bias in analyses. All titles that were published in the volumes listed were thus subjected to equal listing. The choice of period, 1974-1984, and 19912000 was dictated by the desire to erase any bias particularly as it concerns the era of the publications, i.e. first and last decades. The choice was also by convenience.

Simple percentages were used to determine the publication distribution, discipline parameters and authorship distribution.

\section{Result and Discussion}

A total of 787 titles were published in the twenty volumes under study; with 472 titles published during the first decade of the journal and 315 in the last decade (1991-2000).

In the first decade, i.e. Vol. 1-11, it is noteworthy that Vol. 4 (1977) carried the highest number of titles; 80. The least volume was Vol. 11(1984) which published only 1,3 titles. The last decade of publication represented by Vol. 18-27 (19912000) had its highest published titles in 1996 and 1999, i.e. Vols. 23 and 26, wherein 41 articles were published each, with volume 20 credited with only 19 articles. It is important to explain here that the number of articles credited to volume 11 was the publications of its No. 2, as the No. 1 (Vol. 11) was devoted to the abstracts of the proceedings of the $9^{\text {th }}$ annual conference of the Nigerian Society of Animal Production (NSAP), the 
publishers of the Journal. The details of the titles published in the 20 volumes are presented in Table 1.

The manner in which the number of published titles occurred in the subsequent volumes after the first volumes is devoid of any logical explanation. Although it is rational to think that each subsequent volume after an earlier one will increase in number of published titles, this was not the case as titles published in volumes 2 and 3 ( 58 and 47 titles respectively) were lower than volume 1 with 62 titles. Volume 9 (1982) even had a ridiculously low number of published titles, 16 .
This scenario is difficult to explain because of the generally unpredictable turn of events in journal publication in Nigeria.

Four hundred and seventy two (472) titles were published by the jounrnal (NJAP) between 1974 and 1984, while 315 titles were published in the last decade of 1991-2000. This again shows that the journal was more active during its first decade of production than in the last decade. One reason for this low number of output could be said to be the establishment of a sister Journal by the Animal Science Association of Nigeria (ASAN); the Journal, Tropical Journal of Animal Science, which has made effort to compete with the older

Table 1. Distribution of published titles in the Nig. Jounal of Animal Production

\begin{tabular}{cccrr}
\hline Vol. & Year & No. of titles & \% & * \\
\hline 1 & 1974 & 62 & 7.9 & 13.1 \\
2 & 1975 & 58 & 7.4 & 12.3 \\
3 & 1976 & 47 & 5.9 & 9.9 \\
4 & 1977 & 80 & 10.2 & 16.9 \\
6 & 1979 & 17 & 2.2 & 3.6 \\
7 & 1980 & 54 & 6.9 & 11.4 \\
8 & 1981 & 51 & 6.5 & 10.8 \\
9 & 1982 & 16 & 2.0 & 3.4 \\
10 & 1983 & 74 & 9.4 & 15.7 \\
11 & 1984 & 13 & 1.7 & 2.8 \\
18 & 1991 & 23 & 2.9 & 7.3 \\
19 & 1992 & 20 & 2.5 & 6.3 \\
20 & 1993 & 19 & 2.4 & 6.2 \\
21 & 1994 & 34 & 4.3 & 10.8 \\
22 & 1995 & 37 & 4.7 & 11.7 \\
23 & 1996 & 41 & 5.2 & 13.0 \\
24 & 1997 & 37 & 4.7 & 11.7 \\
25 & 1998 & 39 & 4.9 & 12.4 \\
26 & 1999 & 41 & 5.2 & 13.0 \\
27 & 2000 & 24 & 3.0 & 7.6 \\
\hline TOTAL & & & & \\
\hline
\end{tabular}

(There was no publication of Vol. 5, 1978). *Figures under this column represented \% scores of the first and second decades of publication respectively. 
Journals, and the emergence of other related Journals in Nigeria and abroad.

A number of important developments are already available in Nigeria that could contribute to the efficient use of scarce library and information materials. These developments require careful study for its proper adaptability and use. In this study, two options were available for use, i.e. to either study the literature by specie or by discipline, and the latter option was adopted for this study.

All the articles have been grouped into 8 disciplines for the purpose of this exercise and nutritional studies emerged the highest researched discipline, while socio-economics studies were the least researched field. Table 2 below throws more light.

More than $30 \%$ of the total number of articles published by the NJAP are in the area of nutrition. The logical explanation of this is that there are more nutritionists in animal production in Nigeria. A survey through a world bank project on "Who is Who" in the industry is currently on to determine the exact position of this claim. The desire of the pioneer livestock scientists and veterinarians in Nigeria was to attempt to solve the nutritional problems of Nigerians through nutritional studies. This is a reason for the rush into this area of animal production. The incursion of socio-economists in animal production is a latter development which has also been reflected in the number of titles published. This class of scientists has other frontline/relevant journals where they publish apart from livestock-related journals. More of them are often crop based.

\section{Authorship Pattern}

The new trend in scientific publication all over the world is more of joint and multiple authorships than single. A 1969 study on the citation patterns in information science in America observed that more joint and multiple authored references were cited by information scientists in the U.S. than articles by single author (Finichel, 1969). A study by Toye (1975) of Entomologists in Nigeria also confirms this trend and related study by Adewole (1998) in the Journal of Animal Production Research (JAPR) attests to the adoption of this development.

Out of 787 articles considered for this analysis 528 articles $(66.8 \%)$ were jointly authored and the remaining 261 representing $33.2 \%$ were singly authored confirming the adoption of multiple author trend in science and technology by

Table 2. Distribution of articles by discipline in NJAP.

\begin{tabular}{llrc}
\hline No. & Discipline & No. of titles & \% distribution \\
\hline 1 & Breeding \& Genetics & 118 & 15.0 \\
2 & Diseases \& Health & 88 & 11.2 \\
3 & Forage \& Feeds & 35 & 4.4 \\
4 & Management & 49 & 6.2 \\
5 & Nutrition & 289 & 37.0 \\
6 & Products \& General & 84 & 10.6 \\
7 & Reproduction & 102 & 1.3 \\
8 & Socio-Economics & 22 & 2.7 \\
\hline Total & & 787 & 100 \\
\hline
\end{tabular}


Table 3. Status of authorship distribution of publication in N]AP

\begin{tabular}{lrrrrr} 
Vol. & Year & single & $\%$ & Mnltiple & $\%$ \\
\hline 1 & 1974 & 32 & 52.4 & 29 & 47.6 \\
2 & 1975 & 24 & 41.4 & 34 & 58.6 \\
3 & 1976 & 22 & 46.8 & 25 & 53.2 \\
4 & 1977 & 33 & 40.7 & 48 & 59.3 \\
6 & 1979 & 8 & 50 & 8 & 50 \\
7 & 1980 & 20 & 37.1 & 34 & 62.9 \\
8 & 1981 & 21 & 40.4 & 31 & 59.6 \\
9 & 1982 & 7 & 43.8 & 9 & 56.2 \\
10 & 1983 & 28 & 37.8 & 46 & 62.2 \\
11 & 1984 & 1 & 7.7 & 12 & 92.3 \\
18 & 1991 & 2 & 8.7 & 21 & 91.3 \\
19 & 1992 & 2 & 10.0 & 18 & 90.0 \\
20 & 1993 & 5 & 26.3 & 14 & 73.7 \\
21 & 1994 & 10 & 29.4 & 24 & 70.6 \\
22 & 1995 & 3 & 8.1 & 34 & 91.9 \\
23 & 1996 & 9 & 21.9 & 32 & 79.1 \\
24 & 1997 & 13 & 35.1 & 24 & 64.9 \\
25 & 1998 & 10 & 25.6 & 29 & 74.4 \\
26 & 1999 & 9 & 21.9 & 32 & 78.1 \\
27 & 2000 & 2 & 8.3 & 22 & 91.7 \\
\hline Total & & 261 & 33.2 & $\mathbf{5 2 6}$ & 66.8 \\
\hline
\end{tabular}

scientists contributing to the Nigerian Journal of Animal Production (NJAP) where over $66 \%$ of the articles are written by joint or multiple authors. The scenario is the same in all the volumes considered for these analyses.

\section{Institutional Collaboration}

The frontiers of scientific research today have gone beyond national frontiers and have placed more importance on collaboration of interested minds on areas of investigation.

Because of the stage of advancement of science and technology in the developed and developing countries of Europe and the Asia, it is important for Nigerian scientists and technologisis to collaborate with peers from these sides of the world. In a citation analysis study by Adewole 1989) it was observed that scientists that patronize the Journal of Animal Production Research cite more of foreign based journals than Nigerian journals.

From the addresses of 'authors of published titles in NJAP, Nigerian scientists collaborated to publish 63 articles within the Vol. I-II, and 43 articles in Vol. 18-27 with peers from Europe and America. This is a welcome development, as the frontiers of Animal Production Research cut across any national borders.

\section{References}

Adewole, S. (1989). Pattern of citation in the Journal of Animal Production Research 1981-1985. J. Anim. Prod. Res. 9(2): 97107. 
Adewole, S. (1991). Some characteristics of articles published in the Nigerian Journal of Animal Production. J. Anim. Prod. Res. 18(1\&2):27-33.

Dawson, J. (1987). A brief history of the technical services of libraries. Lib. Resources and Tech. Services 6: 197-204.

Finichel, J. (1969). Citation patterns in information sciences. M.A. Thesis, Drexel University, Philadelphia, USA. $129 \mathrm{pp}$.
Toye, B.O. (1975). Some Characteristics of the Nigerian Entomological Literature. Nigerian J. Entomology 3: 173-80.

Vickery, B.C. (1968). Analysis of information. In: Encyclopedia of Library and Information Science. Edited by Allen Kent and Harold Lancour 1(1): 355-384.

(Received 25 July 2001; Accepted 22 $2^{\text {nd }}$ May 2006) 